\title{
Life cycle assessment of façade coating systems containing manufactured nanomaterials
}

\author{
Roland Hischier • Bernd Nowack • \\ Fadri Gottschalk • Ingrid Hincapie • \\ Michael Steinfeldt $\cdot$ Claudia Som
}

Received: 18 March 2014/ Accepted: 22 January 2015

(C) Springer Science+Business Media Dordrecht 2015

\begin{abstract}
Nanotechnologies are expected to hold considerable potential for the development of new materials in the construction sector. Up to now the environmental benefits and risks of products containing manufactured nanomaterials (MNM) have been quantified only to a limited extent. This study aims to assess the potential environmental, health and safety impacts of coatings containing MNM using Life-cycle assessment: Do paints containing MNM result in a better environmental performance than paints not containing MNM? The study shows that the results depend on a number of factors: (i) The MNM have to substitute an (active) ingredient of the initial paint composition and not simply be an additional ingredient. (ii) The new composition has to extend the
\end{abstract}

Electronic supplementary material The online version of this article (doi:10.1007/s11051-015-2881-0) contains supplementary material, which is available to authorized users.

R. Hischier $(\varangle) \cdot$ B. Nowack · I. Hincapie · C. Som Technology and Society Lab (TSL), Swiss Federal Laboratories for Materials Science and Technology (Empa), Lerchenfeldstrasse 5, 9014 St. Gallen, Switzerland

e-mail: roland.hischier@empa.ch

F. Gottschalk

ETSS, 7558 Strada, Switzerland

\section{Steinfeldt}

University of Bremen FB 4/FG 10 Technological Design and Development, Badgasteiner Strasse 1, 28359 Bremen, Germany lifetime of the paint for such a time period that the consumption of paint along the life cycle of a building is reduced. (iii) Releases of MNM have to be reduced to the lowest level possible (in particular by dumping unused paint together with the packaging). Only when all these boundary conditions are fulfilled, which is the case only for one of the three paint systems examined, is an improved environmental performance of the MNM-containing paint possible for the paint compositions examined in this study.

Keywords Manufactured nanomaterial $\cdot$ Life-cycle assessment $\cdot$ Façade coatings $\cdot \mathrm{Nano}^{-\mathrm{TiO}_{2}}$.

Nano-SiO ${ }_{2} \cdot$ Nano-Ag

\section{Introduction}

In the construction sector, nanotechnologies have been expected to hold considerable potential for the development of new materials for some years now (see e.g. BMU 2008). Several studies published in recent years rank this sector among the most relevant ones concerning potential applications of nanotechnology (Teizer et al. 2012). According to Hanus and Harris (2013), "nanotechnology has broad-reaching applications in the construction industry". An important application area is the sector of façade coatings. The paint and coating industry is among the most important consumers of nano-Ag and nano- $\mathrm{TiO}_{2}$ 
(Piccinno et al. 2012). Apart from improving materials' functionalities or the production of materials with completely novel or "multifunctional" properties, the application of manufactured nanomaterials $(\mathrm{MNM})^{1}$ may offer improved environmental performance, i.e. a reduction in the use of hazardous chemical substances, in the consumption of materials, and in the generation of waste (more details e.g. in Teizer et al. 2012, or Hanus and Harris 2013).

The environmental performance of a product can be measured with a life-cycle assessment (LCA) study. According to the ISO 14040 standard (ISO 2006a, b), LCA is a tool to estimate and assess the environmental performance of a material or product, i.e. their potential environmental impacts, as related to a specific question. As stipulated, e.g. in Bauer et al. (2008), one of the key features of an LCA is its socalled 'relative approach', meaning that all inputs and outputs of a system are in relation to the function which is performed. In a first step, all relevant resource and energy inputs and all relevant outputs are summed up in a life-cycle inventory (LCI) model. In the second step, equivalences for the in and output flows in certain impact categories are calculated within the life cycle impact assessment (LCIA) step in order to determine the potential environmental impacts of the examined system. Nowadays, LCA is seen as the "most established and well-developed tool" for the sustainability assessment of production and consumption of goods and services (Ness et al. 2007). However so far, only few LCA studies of nano-products have been published, as shown in several recent review articles (Gavankar et al. 2012; Hischier and Walser 2012; Upadhyayula et al. 2012). The majority of these LCA studies are far away from what is considered nowadays 'comprehensive' LCA studies: they cover only the production of the products, and releases of MNM are neglected in almost all studies according to these review articles. Thus, one of the objectives of this LCA study is to go one step further by taking into

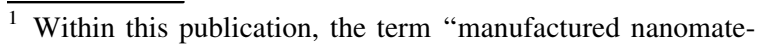
rials" and its abbreviation "MNM" are used according to the definition of the European Commission (EC 2011) indicating that this term designates all those manufactured materials "containing particles, in an unbound state or as an aggregate or as an agglomerate and where, for $50 \%$ or more of the particles in the number size distribution, one or more external dimensions is in the size range $1-100 \mathrm{~nm}$ ".
}

account the whole life cycle of a product and the potential releases of MNM along this life cycle.

Nowadays, potential environmental, health and safety (EHS) impacts of coatings containing MNM (like e.g. nano- $\mathrm{TiO}_{2}$, nano-Ag or nano-SiO${ }_{2}$ ) should be addressed in a holistic and prospective manner during the whole life cycle, based on a novel concept of life cycle thinking, bringing together two complementary aspects: the investigation of risks and opportunities during the product life cycle (Nowack 2009; Köhler et al. 2008) as well as a LCA study according to the ISO 14040 standard (ISO 2006a). This publication focuses on the latter aspect (i.e. the LCA study) and is investigating whether an integration of MNM in façade coatings really leads to an improved environmental performance of such coating products. This is done in the framework of LCA studies of various façade coatings containing nano- $\mathrm{TiO}_{2}$, nano-Ag and nano- $\mathrm{SiO}_{2}$, by comparing each of them to a respective façade coating without the respective MNM. A subsequent, more holistic evaluation of these coating products (by applying e.g. the multi-criteria decision analysis framework described in Linkov and Seager (2011), with these LCA results) is an element of a further step.

Therefore, the first part of the paper gives an overview of the goal and scope definition for the established LCA studies. This is followed by a short description of the various foreground processes, as well as the common methodology for the estimation of releases of nanoparticles along the life cycle. The subsequent sections give an overview of the most important results on a case by case basis and summarise the discussion of these results.

\section{Goal and scope definition}

The overall goal of this LCA study is the establishment of a comprehensive ecological comparison of façade coatings with and without MNM (as one of their ingredients) along the complete life cycle. For this, three different, generic paint systems (paint A to C) are examined independently from each other. "Generic", as the composition of each system has been defined by partners from the paint industry specifically for the project, representing a typical composition of outdoor and indoor façade coatings, respectively. Within each of these paint systems, one paint containing MNM 
(nano- $\mathrm{TiO}_{2}$ in paint system $\mathrm{A}$, nano-Ag in system $\mathrm{B}$, and nano- $\mathrm{SiO}_{2}$ in system $\mathrm{C}$ ) is compared with a respective paint composition not containing any kind of MNM. A total of six different paints (based on three different basic compositions) are examined in this study. The three systems represent thereby two different "approaches" for the use of MNM in façade coatings. System A is an example of a "substitution" case, because the MNM (here: nano- $\mathrm{TiO}_{2}$ ) is substituted for parts of another (active) ingredient (here: pigment-grade $\mathrm{TiO}_{2}$ ). The systems $\mathrm{B}$ and $\mathrm{C}$ represent "addendum" cases, i.e. the MNM (here: nano-Ag and nano- $\mathrm{SiO}_{2}$ ) are added to a basic composition (resulting in a reduction in the solvent or the fillers of the respective basic composition).

Table 1 gives an overview of the examined painting formulas according to their application fields, lifetime, as well as their most important ingredients. The reported increase in lifetime for the paints A1 and $\mathrm{C} 1$ - a primary objective for the involved companies-results from a photocatalytic self-cleaning effect of $\mathrm{A} 1$ and a better scratch resistance $(\mathrm{C} 1)$ that these paints offer in an outdoor application due to the use of MNM. In system B, the use of MNM has an antimicrobial effect, which will result in a healthier environment in the room where the paint is applied.

The focus of this study was to understand on a general level whether MNM-enhanced paints have a better environmental performance compared to a respective paint not containing MNM. Therefore, we did not undertake any comparison between the various systems (i.e. a comparison of the various MNM against each other in the context of their application in paints).

The "protection of one square meter of (indoor or outdoor) wall during a period of 80 years" was chosen as the functional unit, i.e. the unit which defines what is being studied, thus providing a clear reference to which all the inputs and outputs can be related (Rebitzer et al. 2004). The chosen time horizon of 80 years represents thereby a typical life expectation for modern buildings according to the information from professionals of the Swiss construction sector. Hence, the two outdoor paint systems described in Table 1 result in three applications of the paints containing MNM (i.e. paint A1 and C1, which have a lifetime of 27 years), and four applications in the case of paints $\mathrm{A} 2$ and $\mathrm{C} 2$ (i.e. paints without MNM) as their lifetime is 20 years only. In the case of the indoor system (i.e. paints B1 and B2), no difference in the number of applications was assumed. Each one would have to be applied eight times during the whole lifespan of the building, as each of them lasts 10 years after the application. These two paints do not differ in lifetime but, according to the industry representatives, a more healthy environment inside the room in case of an application of a paint containing MNM (i.e. paint B1) can be expected. The reported lifetime data were the result of extensive discussions with industry representatives during the first part of this project.

The examined system contains all the precursors requested in order to produce these six different paints (i.e. starting from the extraction of the resources for producing all components of the paints) as well as all
Table 1 Main

characteristics of examined façade coatings (according to industrial partners)

a Assumption (result of a discussion with representatives from the paint industry): in outdoor applications MNMcontaining paints have a $30 \%$ longer lifetime; in indoor applications no longer lifetime is assumed

\begin{tabular}{|c|c|c|c|c|c|c|}
\hline & Paint A1 & Paint A2 & Paint C1 & Paint C2 & Paint B1 & Paint B2 \\
\hline MNM integration philosophy & \multicolumn{2}{|c|}{ "Substitution" } & \multicolumn{2}{|c|}{ "Addendum" } & \multicolumn{2}{|c|}{ "Addendum" } \\
\hline Application field & Outdoor & Outdoor & Outdoor & Outdoor & Indoor & Indoor \\
\hline Lifetime [years] & $27^{\mathrm{a}}$ & 20 & $27^{\mathrm{a}}$ & 20 & $10^{\mathrm{a}}$ & 10 \\
\hline \multicolumn{7}{|l|}{ Composition $[\% w / w]$} \\
\hline MNM-content & 3.0 & - & 5 & - & 0.3 & - \\
\hline Type of MNM & $\mathrm{TiO}_{2}$ & - & $\mathrm{SiO}_{2}$ & - & $\mathrm{Ag}$ & - \\
\hline $\mathrm{TiO}_{2}$, pigment-grade & 13.58 & 16.58 & - & - & - & - \\
\hline Silicone defoamer & 10.97 & 10.97 & 0.3 & 0.3 & 0.6 & 0.6 \\
\hline Styrene/acrylic copolymer & 14.62 & 14.62 & 23.3 & 23.3 & 28.1 & 28.1 \\
\hline Calcium carbonate (filler) & 31.75 & 31.75 & 46 & 46 & 33.2 & 33.5 \\
\hline Talcum (filler) & 6.58 & 6.58 & - & - & 10.1 & 10.1 \\
\hline Further ingredients & 5.2 & 5.2 & 1.7 & 1.7 & 2 & 4.7 \\
\hline Water & 11.3 & 14.3 & 15.2 & 28.7 & 23 & 23 \\
\hline
\end{tabular}


subsequent life stages after the application of the paint, up to the final disposal. An overview of the resulting system boundaries, including the distinction between foreground and background system (i.e. processes that are modelled specifically for this study: the foreground system, and processes covered with average data: the background system) is given in Fig. 1.

The main data sources for the foreground processes listed in Fig. 1 are direct inputs from the paintproducing industry. In the cases without enough detailed information, we used additional literature and survey outcomes in order to cover specific points/ questions. A detailed description of the modelling of all the foreground processes can be found in the next section. For the listed background processes in Fig. 1, data from the database ecoinvent v2.2 (ecoinvent Centre 2010) were used as far as possible. For materials where ecoinvent does not contain specific data, respective proxies were identified or new gate-togate datasets were developed. The latter is the case for (pigment-grade) titanium dioxide, talcum and the styrene/acrylic copolymer. These new LCI datasets are described in detail in the Supplementary materials of this paper.

On the level of the subsequent impact assessment step, two of the most up-to-date methods in this area were applied: the ReCiPe method (Goedkoop et al. 2012) and the USEtox model (see e.g. Rosenbaum et al. 2008). ReCiPe is a very convenient way of presenting the results on a midpoint and an endpoint level. This large choice allows the fulfilment of the requirements of the ISO 14040/44 standards (ISO 2006a, b), which asks for a "selection of impact categories that reflects a comprehensive set of environmental issues related to the product system being studied, taking into account goal and scope". The second method applied-i.e. the USEtox model-is the international consensus model for the assessment of toxicity. The whole system was modelled with the LCA software tool Open LCA and the imported database ecoinvent data v2.2 (ecoinvent Centre 2010). For the impact assessment methods USEtox and $\mathrm{ReCiPe}$, the ecoinvent implementation of version v2.2 (November 2010) was used.

\section{Inventory analysis}

As shown in Fig. 1, the foreground system distinguishes among six different life-cycle stages, which were modelled as following in this study:

- Production of MNM The coverage of the production of the used MNM (nano- $\mathrm{TiO}_{2}$, nano-Ag and nano- $\mathrm{SiO}_{2}$ ) by actual production data from industry was not possible in this project due to a

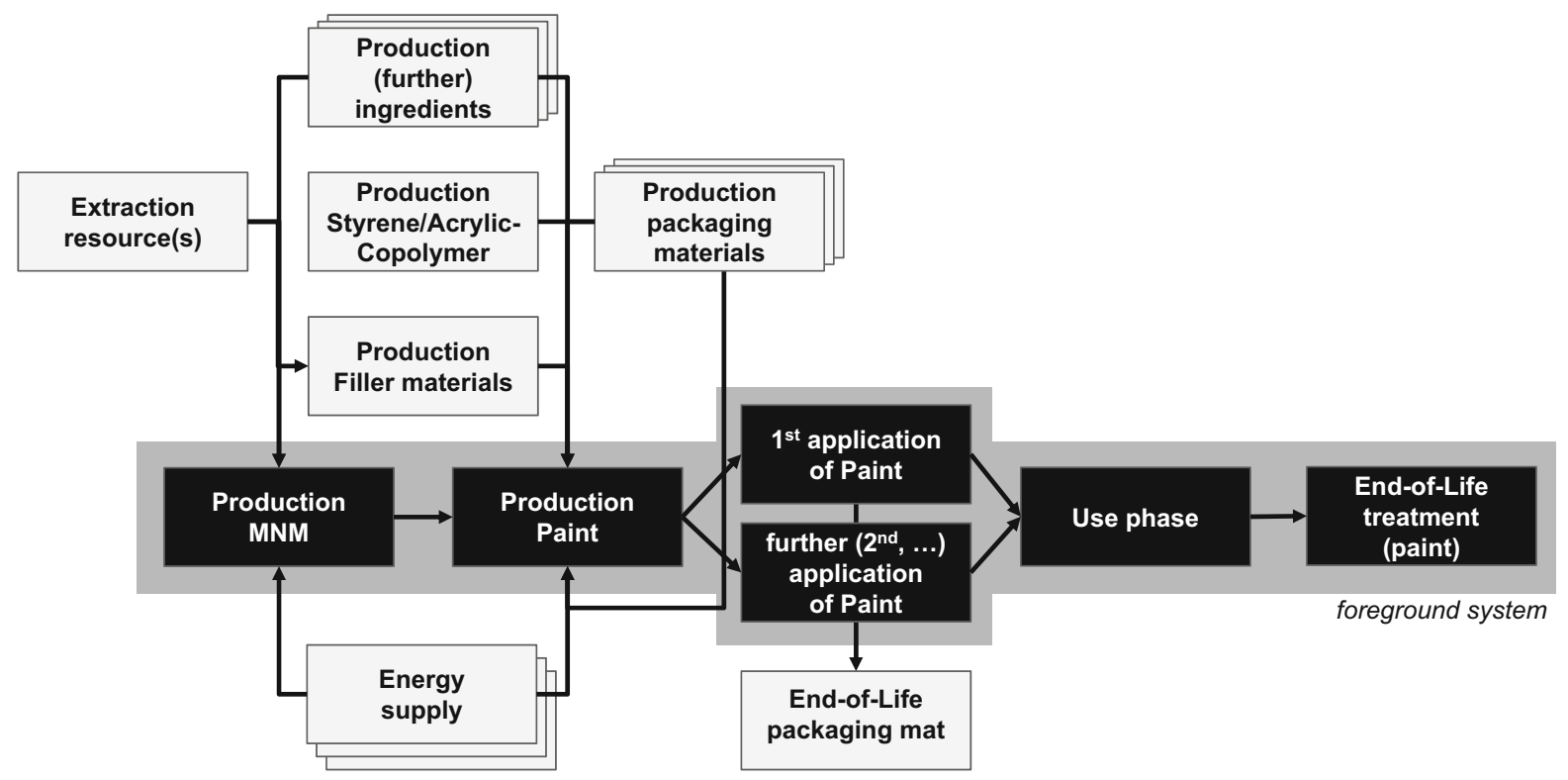

Fig. 1 Examined system for the comparison of façade coating systems-with a distinction between the foreground (black) and the background systems (grey) 
lack of respective feedback from the companies. Thus, for nano- $\mathrm{Ag}$ and nano- $\mathrm{SiO}_{2}$, respective data from literature (Walser et al. 2011; Roes et al. 2010) were used. For nano- $\mathrm{TiO}_{2}$, a new, proper dataset based on the sulphate process route was established. More details about this new dataset can be found in the Supplementary Materials of this paper.

- Production of paint Data obtained directly from the paint industry were used for the production of the various paints. These data include energy and material flow data for the mixing of the various ingredients of the examined paintings. The actual data were considered "confidential" by the companies providing these numbers. Furthermore, $5 \mathrm{~L}$ plastic buckets were added as packaging, based on data retrieved from a producer's website.

- 1st application of paint (i.e. first coating of the wall) This step was based on experimental settings showing an average application of $0.35 \mathrm{~kg} / \mathrm{m}^{2}$ of paint on the wall. The application was assumed to be done with a roller resulting in no losses during the application; except the $0.15 \mathrm{~L}$ of paint that remain in the roller at the end of the day. According to experts from the paint industry, the roller is then not cleaned, but ends up in the waste. Thus, these $0.15 \mathrm{~L}$ of paint were assumed to be disposed (together with the roller) in an incineration plant. It was assumed that $1.5 \%$ of the paint remains in the bucket and thus, it gets disposed together with a residual paint portion. Again a disposal via incineration was assumed. A transport distance of $200 \mathrm{~km}$ from the point of production to the point of application was assumed in this study for all six different paint formulations.

- 2nd and all following applications For this process, a reduced consumption of only $75 \%$ (compared to the 1st application) was assumed, due to the fact that these applications take place on the same wall (over the already existing paints). All further aspects were treated similarly as for the first application (i.e. as described above).

- Use phase This process step covers the time during which the paint stays applied to a wall that is exposed to respective environmental stressors (e.g. weather, etc.). Weathering-related releases of nanoparticles were also integrated, based on experimental results about release of $\mathrm{TiO}_{2}$ from paint A1 reported in Al-Kattan et al. (2013).
Releases of any kind of bulk particles (from pigment-grade $\mathrm{TiO}_{2}$ or any other ingredient of the paint formulations) were not taken into account. These releases were assumed to be identical for the two paint formulations examined in each of the three paint systems.

- End-of-life treatment of the paint Based on information about the end-of-life treatment in the construction sector in Switzerland (used as basis for the modelling of this sector within the database ecoinvent data v2.2 and described in Doka 2007), the end-of-life treatment of the various paints examined was modelled, resulting in $85 \%$ of the paint fraction ending-up in a sanitary landfill (and $15 \%$ as unwanted elements in the recycled fraction). Case-specific landfill datasets are calculated for all six paint compositions examined here with the support from the XLS tools of the ecoinvent Centre (Doka 2007).

Along all these different life-cycle stages, a common modelling approach for eventual releases of nanoparticles was applied. However, the release rates and concentrations of MNM are not very well known and have only been studied experimentally and/or analytically to a very limited extent so far (Gottschalk et al. 2013). Thus, release scenarios based on a stochastic (probabilistic) material flow model, oriented towards a complete life-cycle analysis of the MNM produced and used in paints were developed. The information for these modelled scenarios is based on experimental evidence produced in this project, on literature data, on environmental release categories (ERC) of the European technical guidelines from the European Chemicals Agency (ECHA 2010), on inputs from the industrial partners in this project, and on assumptions based on our own experience. In order to cover as much of the spectrum of likely releases as possible, two scenarios-representing realistic and high-release factors-were developed. Taken together, these two scenarios reflect the entire possible release (and environmental concentration) spectrum. Both of these scenarios are determined by inherent release volume uncertainties and in addition are influenced by the distinct uncertainty related to the application and manufacturing quantities of the MNM. Furthermore, based on these data, a computer-based modelling can be performed in order to derive predicted environmental concentrations (PEC) of the MNM caused when this 
compound is applied in and produced for paint coatings; knowing such PECs is crucial when one is estimating the environmental risks of MNM. More details concerning the actual derivation and the references of all values in these two scenarios and the different MNM used in the three paint systems can be found in the Supplementary Materials of this paper. The values for the LCA model of paint A1 derived from this (using the "realistic case" scenario) are summarised in Table 2.

\section{Results}

Paint system A (nano- $\left.\mathrm{TiO}_{2}\right)$

Figure 2 shows the impact of the paint system A according to the functional unit reported in "Goal and scope definition" section, i.e. the impact per one square metre of wall, protected over a time period of 80 years. Figure 2 shows a quite similar behaviour for all the examined mid- and endpoint indicators between paint $\mathrm{A} 1$ (containing $\mathrm{TiO}_{2}$ in nano- and in pigmentgrade form) and paint A2 (containing only pigmentgrade $\mathrm{TiO}_{2}$ ). All the factors show about $20 \%$ less impact for the system A1. That comes mainly from the fact that in case of paint A1, according to the key data given in Table 1, the façade needs to be painted one time less during the 80 years lifetime of the façade. The impact from the production of the used amount of nano- $\mathrm{TiO}_{2}$ contributes in all examined factors to less than $10 \%$ to the total impact (compared to the impact of the system of paint A2). The application of the paint (including the transport efforts from the place of production) use and end-of-life treatment together contribute even less to the total impact.

In Fig. 2, no releases of nanoparticles are taken into account for the two USEtox factors for ecotoxicity and human toxicity. The publications from the USEtox team (i.e. Rosenbaum et al. 2008; Huijbregts et al. 2010a) do not contain any characterisation factors for this kind of releases. However, in a recent $\mathrm{PhD}$ thesis, two factors for freshwater ecotoxicity of nano- $\mathrm{TiO}_{2}$ releases were published (Salieri et al. 2015). Assuming a constant ratio between the ecotoxicity characterisation factors for emissions to water, air and soil of inorganic substances (as observed for the intermediate characterisation factors for inorganic emissions, reported by Huijbregts et al. 2010b), related characterisation factors for releases of nano- $\mathrm{TiO}_{2}$ to air and soil were estimated. Applying these factors results in the impacts shown in Fig. 3.

In order to analyse this figure, the "default option" (i.e. second diagram from top in Fig. 3, and according to the releases from Table 2) has to be taken as starting point. For this option, we assumed that the release scenario "realistic case" is appropriate, that long-term nano releases (i.e. releases taking place between 100 and 100,000 years after landfilling) behave in a manner similar to titanium and that the higher value reported in Salieri et al. (2015), is applied as characterisation factor (i.e. as factor representing the environmental impact related to $1 \mathrm{~kg}$ of an emitted substance). Under these assumptions, Fig. 3 shows an overall impact for paint A1 that is almost of the same order as the respective impact from paint $\mathrm{A} 2$, when assuming a lifetime of 27 years for paint A1. As soon as the lifetime becomes shorter-resulting in a loss of the smaller consumption for paint A1-the ecotoxicity potential from paint A1 rises about $20 \%$ higher than the one from paint $\mathrm{A} 2$, when these nano releases are included. On the other hand, having a much longer lifetime for paint A1, combined with a further reduction in the overall consumption, would lead to a clear reduction of the ecotoxicity potential compared to paint A2. With the three other diagrams, Fig. 3 shows the consequences and the influence of the exclusion of long-term nanoreleases (top diagram), the influence of

Table 2 Releases of nano- $\mathrm{TiO}_{2}$ particles along the life cycle (more details concerning the derivation of the values: see Supplementary Materials) in case of the "realistic case" scenario

\begin{tabular}{llllll}
\hline & & To air & To water & To water (long-term) & To soil \\
\hline Production $\mathrm{TiO}_{2}$ powder & $\mathrm{kg} / \mathrm{kg} \mathrm{TiO} 2$ & $4.6 \mathrm{E}-08$ & 0.00032 & 0.00689 & - \\
Manufacture of coating & $\mathrm{kg} / \mathrm{kg}$ paint & $3.0 \mathrm{E}-10$ & $1.63 \mathrm{E}-06$ & $4.49 \mathrm{E}-05$ & - \\
Application (i.e. painting) & $\mathrm{kg} / \mathrm{m}^{2}$ applied paint & $1.5 \mathrm{E}-09$ & $6.4 \mathrm{E}-07$ & $2.2 \mathrm{E}-04$ & - \\
Use phase (w/o application) & $\mathrm{kg} / \mathrm{m}^{2}$ (over 80 years) & - & $3.5 \mathrm{E}-05$ & - & $3.5 \mathrm{E}-05$ \\
End-of-life (landfilling) & $\mathrm{kg} / \mathrm{kg}$ paint disposed & $6.0 \mathrm{E}-08$ & $2.59 \mathrm{E}-05$ & 0.00899 & - \\
\hline
\end{tabular}




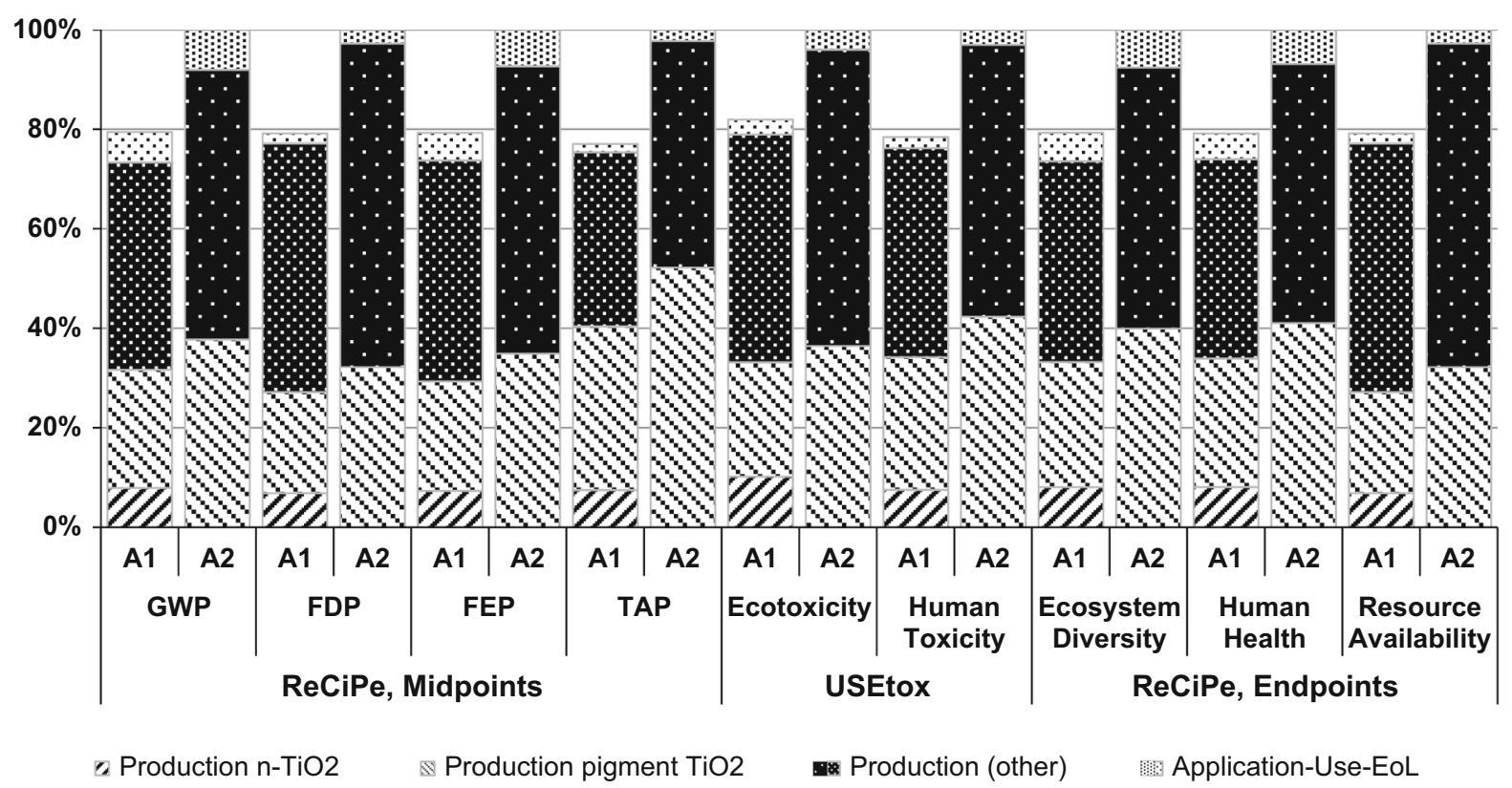

Fig. 2 Environmental impact of the complete life cycle (from paint production to its final disposal) for the protection of $1 \mathrm{~m}^{2}$ of wall during 80 years with the paints $A 1$ and $A 2$, shown relative to the highest impact $(=100 \%)$ within each factor. Following indicators are shown: the ReCiPe midpoint indicators

a change in the release scenario (third diagram from top), as well as the influence of the applied characterisation factor (bottom diagram) on the results for paint A1. These diagrams show that the use of the so-called "high release case" scenario in combination with the high characterisation factor leads in the end to a result for paint $\mathrm{A} 1$ that is a factor 2-3 higher than the impact from paint A2. In the end, the result stands and falls actually with the characterisation factor applied.

Paint system B (nano-Ag)

In Fig. 4, the results for $1 \mathrm{~m}^{2}$ of wall protected during 80 years for the indoor paint system B are shown. The lifetime (on the wall) of B1 and B2 is the same and also the formulations are quite similar, except that paint B1 contains nano-Ag and paint B2 contains no silver at all in any form.

Comparing the two paints B1 and B2 shows always the lowest values for the latter one. When focusing on $\mathrm{ReCiPe}$, in most cases, the impact of B1 is about $30-100 \%$ higher than the related impact of paint B2. An exception is the acidification potential (TAP) and with this also the ReCiPe Endpoint "Human global warming potential $(G W P)$, freshwater eutrophication potential $(F E P)$, fossil fuel depletion potential $(F D P)$ and terrestrial acidification potential $(T A P)$, the two toxicity factors from the USEtox model, as well as the three damage categories from ReCiPe endpoint method

Health" (containing acidification as one of its elements) - because here the impact of paint B1 is almost three times higher than the one from B2.

And again similar as for nano- $\mathrm{TiO}_{2}$ in Fig. 2, no releases of nanoparticles are taken into account for the two toxicity factors shown in Fig. 4. However, the two toxicity factors of paint B1 (containing nano- $\mathrm{Ag}$ ) show already four and more times higher impacts than the system B2. Thus, an assessment of the nano releases will not change this result anymore. The paint B2 causes clearly less toxicological impacts than B1.

Paint system $\mathrm{C}$ (nano- $\mathrm{SiO}_{2}$ )

The environmental impacts from the outdoor paint system $\mathrm{C}$ (with $\mathrm{C} 1$ using nano- $\mathrm{SiO}_{2}$ ) are shown in Fig. 5. The figure shows also in this case the environmental impact per one square metre of wall, protected over a time period of 80 years. With $\mathrm{C} 1$, the façade needs to be painted one time less during the 80 years lifetime of the façade compared to $\mathrm{C} 2$. As the production of nano- $\mathrm{SiO}_{2}$ (characterised by an average of the three wet pathways documented in Roes et al. 2010) represents a multi-output process of two-due 
Fig. 3 Ecotoxicity Potential (expressed in CTU: comparative toxic units) of the paints $A l$ and $A 2$ along the complete life cycle for the protection of $1 \mathrm{~m}^{2}$ of wall during 80 years. The result of paint Al is shown as a function of its lifetime (24, 27 and 40 years), additionally as a function of an inclusion (or not) of long-term (LT) releases, the actual release scenario and the characterisation factor used for the releases of nano$\mathrm{TiO}_{2}$ particles

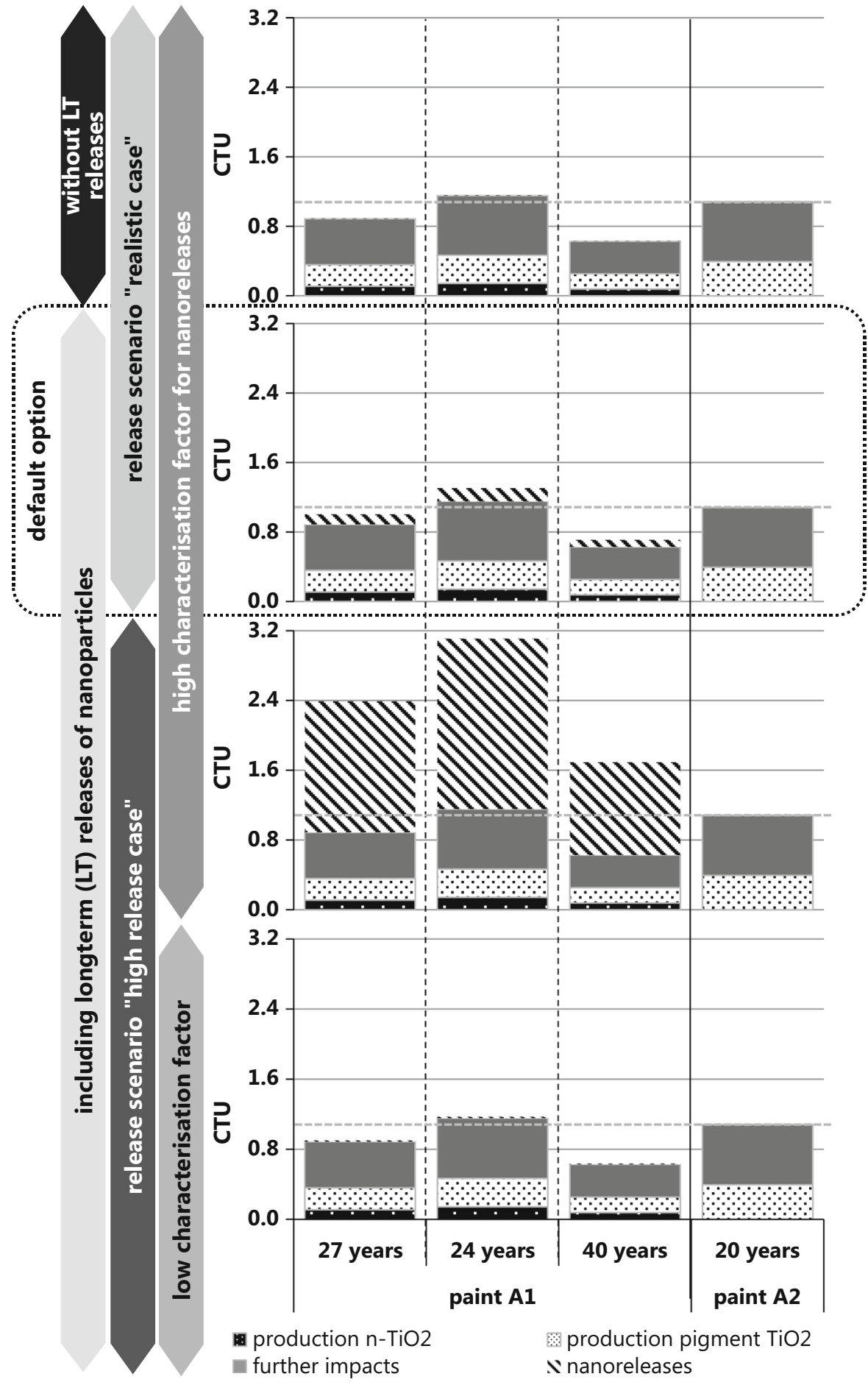

to their price-very different chemical substances (i.e. nano- $\mathrm{SiO}_{2}$ and sodium sulphate), an economic allocation seems to be the most adequate procedure here. In Fig. 5, the results in the case of mass-based allocation are shown as well. This latter allocation method shows lower results for the paint $\mathrm{C} 1$ compared to the default, i.e. economic allocation procedure. 


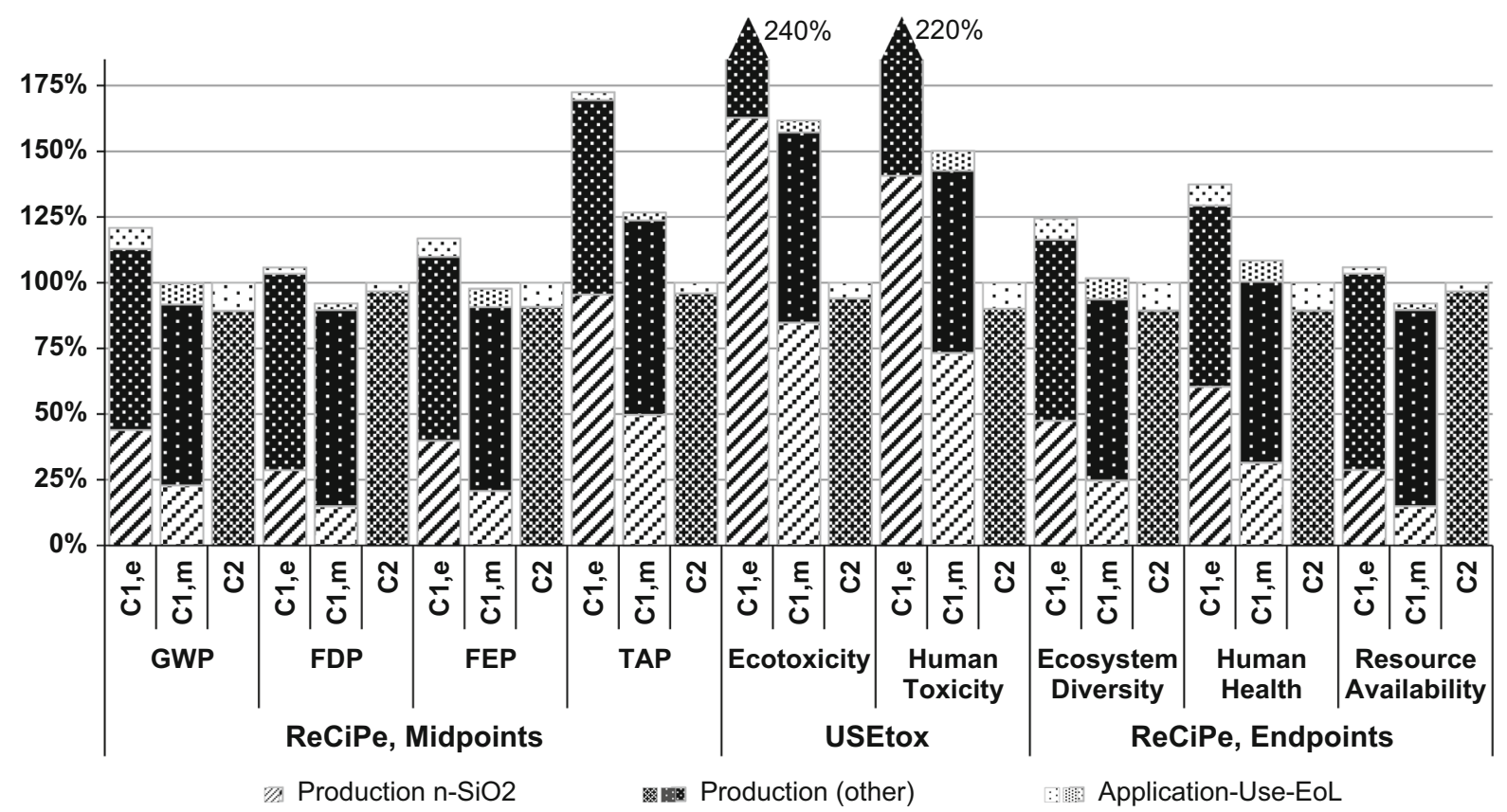

Fig. 4 Environmental impact of the complete life cycle (from paint production to its final disposal) for the protection of $1 \mathrm{~m}^{2}$ of wall during 80 years with the paints $B 1$ and $B 2$, shown relative to the impact of paint $B 2(=100 \%)$ for each factor. The same factors as in Fig. 2 are shown

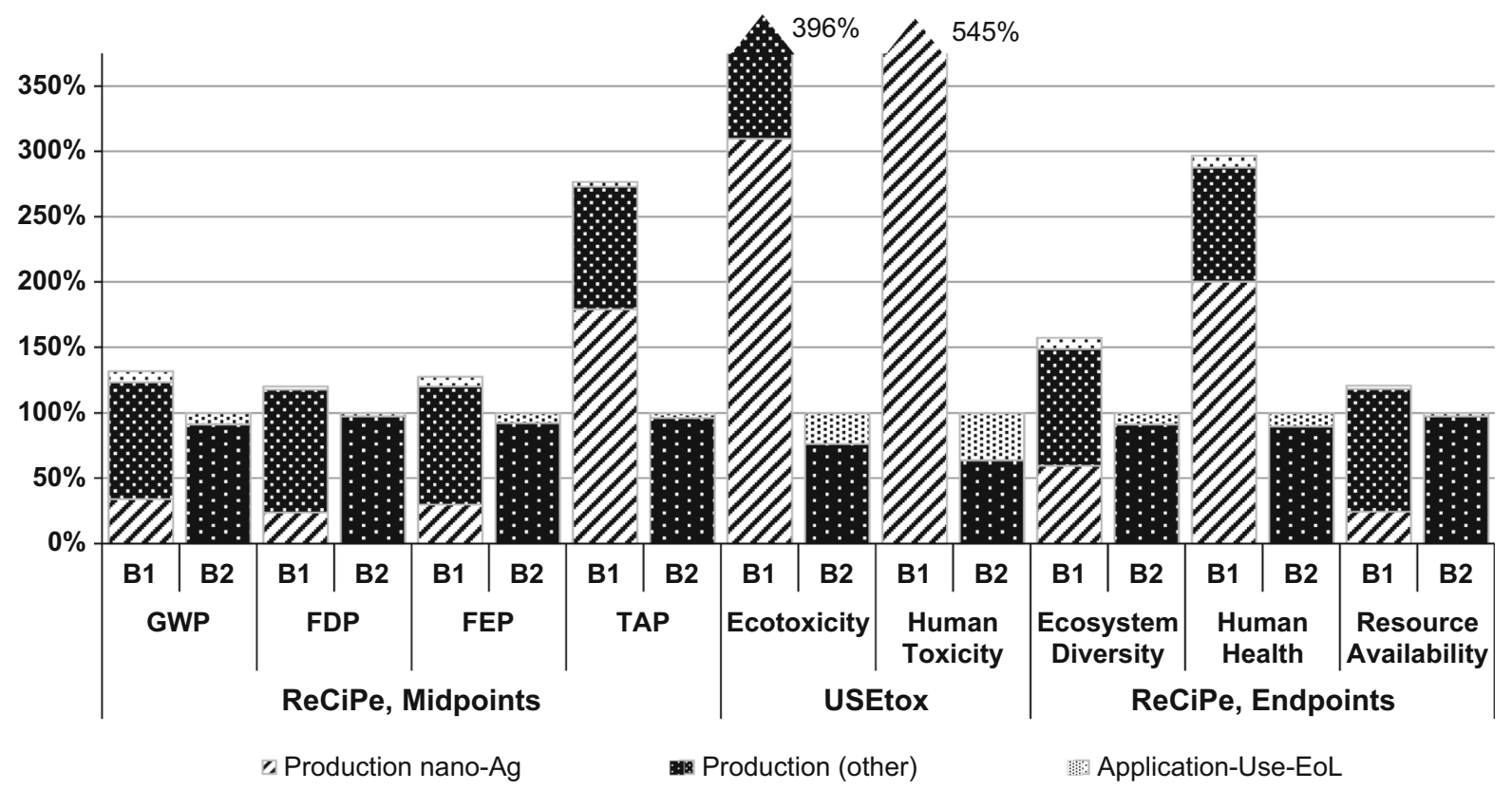

Fig. 5 Environmental impact of the complete life cycle (from paint production to its final disposal) for the protection of $1 \mathrm{~m}^{2}$ of wall during 80 years with the paints $C 1$ (shown with two different allocation schemes for the production of nano- $\mathrm{SiO}_{2}$ : economic allocation $(C 1, e)$ and mass-based allocation $(C 1, m))$ and $C 2$, shown relative to the impact of paint $C 2(=100 \%)$ for each factor. The same factors as in Fig. 2 are shown 
When the two paints $\mathrm{C} 1$ and $\mathrm{C} 2$ are compared, paint $\mathrm{C} 2$ shows always the lowest values. At the same time it can be seen that there are several midpoints and endpoints for which it is not possible to say that either of the two systems has an advantage; the differences are simply too small in order to be able to treat this as a difference. This is the case, e.g. for consumption of fossil fuels (FDP) and the corresponding endpoint (i.e. resource availability); but also in case of global warming (GWP), eutrophication (FEP) or the endpoint ecosystem diversity, the differences between $\mathrm{C} 2$ and $\mathrm{C} 1$ are a maximum of $25 \%$, a value that most probably is insignificant (due to the rather high uncertainty in the inventory between the two examined façade coating systems).

In Fig. 5, in a manner similar to that for nano- $\mathrm{TiO}_{2}$ in Fig. 2 and for nano-Ag in Fig. 4, no releases of nanoparticles were taken into account for the two toxicity factors. However, the two toxicity factors of paint $\mathrm{C} 1$ (containing nano- $\mathrm{SiO}_{2}$ ) show even when applying mass-based allocation factors an impact that is already more than $50 \%$ higher compared to the impact of paint $\mathrm{C} 2$. Thus, an assessment of the MNM releases will not change the advantage of paint $\mathrm{C} 2$ in comparison with paint $\mathrm{C} 1$.

\section{Discussion}

The core question in this study is how the inclusion of a MNM in the paint composition influences the overall environmental performance of the paint along its complete life cycle. It is obvious that each additional ingredient results in an additional production impact. However, such an additional ingredient can either replace an already existing ingredient (like in paint system $\mathrm{A}$, where nano- $\mathrm{TiO}_{2}$ replaces a similar amount of pigment-grade $\mathrm{TiO}_{2}$ ) or be truly a supplementary ingredient (like in paint system $\mathrm{C}$, where nano- $\mathrm{SiO}_{2}$ is added, replacing parts of the basic solvent, i.e. of water).

The analysis of the three case studies allowed us to identify three relevant issues in relation to the above core question of the study, i.e. the 'lifetime' (prolongation), the 'releases of nanoparticles' along the complete life cycle and the issue of 'long-term emissions' in the end-of-life treatment.

\section{Lifetime (prolongation)}

Whether the MNM is a substitute or an addendum in the paint has a great influence on the relevance of the effects due to the lifetime prolongation. Let us examine first the example of paint system A, i.e. the case of the MNM being a "substitute": The variation of the lifetime of paint A1, shown for the factor "ecotoxicity potential", shows that the production efforts of nano- $\mathrm{TiO}_{2}$ are slightly higher than those of the same amount of pigment-grade $\mathrm{TiO}_{2}$. Hence, an environmental advantage results from this change in the composition only if the properties of the MNM lead to a real reduction of the paint quantity consumed over the total lifetime of the building. The latter is actually the case when the default scenario of paint A1 is used. The examined paint system A then shows a high sensibility concerning the extension of its lifetime because only a lower number of applications during the lifetime of the building leads for this paint really to an ecological gain due to the use of MNM. In paint system $\mathrm{C}$, the situation is completely different because there the nano- $\mathrm{SiO}_{2}$ slurry replaces only one part of the water used in the paint. It seems obvious that such a substitution is much less favourable for the MNM-containing paint (compared to a similar composition without MNM), and the results from paint system C confirm this. Despite the fact that the same boundary conditions as those for paint system A are used (i.e. there is a lower consumption of paint $\mathrm{C} 1$ assumed, as this paint lasts longer on the wall), the results show no reduction in the environmental impacts from paint $\mathrm{C} 1$. In contrast, there are factors (like e.g. the midpoint factors for acidification, ecotoxicity and human toxicity, as well as the endpoint factor on 'human health' damage) where paint C1 shows a clearly higher impact. This conclusion is thereby independent from the allocation principle used within the production pathway for nano- $\mathrm{SiO}_{2}$. The third paint system $B$ is a second example for adding the MNM to an existing composition and shows a quite similar picture as system C. However, in contrast to system $\mathrm{C}$, the result here is only due to the added MNM as the amount used for paints B1 and B2 is similar (the model assumes in this case no prolongation of the lifetime due to the use of an MNM). Based on the examinations done in this study, it is however not possible to make any type of forecast concerning the influence of nano- $\mathrm{SiO}_{2}$ or nano- $\mathrm{Ag}$ in a substitution situation (like e.g. nano-Ag replacing Trichlosan as antimicrobial ingredient in paints) as such a scenario would depend very much on the actual specification of such a substitution. Hence, specific 
cases need to be examined when an answer to such a question is of interest. A comparison of nano-Ag and Trichlosan in the textile sector, for T-Shirts, however, can be found in a publication from Walser and coworkers (Walser et al. 2011).

\section{Releases of nanoparticles}

The release of nanoparticles is a parameter that can influence the environmental impacts even more than the prolonged lifetime, as shown in this study for the case of nano- $\mathrm{TiO}_{2}$. Then the influence of the abovediscussed lifetime prolongation stays on the order of $20 \%$ only, while the impact assessment of the actual release amounts can lead to a variability of the result of almost a factor of three. This factor results from the comparison of a realistic release scenario, assessed with the lower value reported for the characterisation factor of nano- $\mathrm{TiO}_{2}$ releases, to a high-release scenario, assessed with the upper value for this characterisation factor.

The high variability of this factor is actually related to the great uncertainties concerning the actual releases of MNM along the product life cycle as well as their characterisation factors (i.e. the fate, exposure and hazard data for the respective MNM). The first issue is therefore mainly a question of having more detailed information about the examined system, e.g. the amount of unused paint that results, together with the packaging or applying instruments (rollers etc.) in the incineration. The second point is related to a technique presenting a more adequate modelling of these MNM releases by including physicochemical properties of MNM that are relevant for fate, exposure and hazard, as proposed in Hischier (2014); that technique allows one to perform a more precise calculation of characterisation factors as functions of these properties. But first, research has to be done in this direction in addition to the proposal in Hischier (2014), concerning these additional properties. Similarly, rough estimations for the two other MNM are not possible, as there are no characterisation factors available thus far for releases of nano- $\mathrm{Ag}$ and nano-SiO $\mathrm{S}_{2}$. Again, it has to be stressed that only releases of the nanoparticles have been in the focus (releases of all the remaining ingredients of the paint systems examined were not taken into account). This exclusion of all further releases is justified by the fact that they would be about equal for the two respective paint systems (i.e. for paints $\mathrm{A} 1$ and $\mathrm{A} 2$, etc.); as all these further ingredients are kept more or less constant in each examined paint system. Comparing in the case of nano-Ag the results of this study with the results for a T-shirt (described in Walser et al. 2011), containing nano-Ag due to its antimicrobial efficacy, shows quite a different picture for the two LCIA factors reported in Walser et al. (2011), i.e. Global Warming and Ecotoxicity (both from the ReCiPe Midpoint LCIA method). This study has reported in both cases a clear dominance for the production of the nano-Ag-containing paint-being 93 (GWP) and $98 \%$ (Ecotoxicity) of the total impactwith the nano-Ag production alone being 26 (GWP) and $93 \%$ (Ecotoxicity) of the total impact. The T-shirt study of Walser and co-workers, on the other hand, shows the main impact clearly for the subsequent use phase. For GWP, this can be explained to a large extent by the energy consumption of the washing machine (the use phase of the paint does not contain comparable impacts). In the case of ecotoxicity, the impact of the examined paint is due to the releases of $\mathrm{Ag}, \mathrm{Mn}, \mathrm{Zn}$ and $\mathrm{Ni}$ ions into the water (responsible together for almost $80 \%$ of the impact). Hence, taking into account the release of Ag during the washing process in Walser et al. (2011), is key for the dominance of the use phase for this impact category.

Another important issue when dealing with releases of nanoparticles is occupational health-i.e. the exposure of workers dealing with the production and use of such MNM. As for bulk emissions, the LCA framework is not yet established enough to take this issue into account (i.e. indoor releases and their related impacts on, e.g. human health). Thus, this point is not in the focus of this study, but will be part of a forthcoming, more holistic evaluation of these coating products.

\section{Long-term emissions}

Last but not least, another parameter that is influencing the results of the different paint systems examined here is identified, i.e. the effects from long-term emissions in the final landfilling facilities. So far the behaviour of NMN in landfills has received almost no attention (Asmatulu et al. 2012) and only a few experimental data are available (e.g. Bolyard et al. 2013; Khan et al. 2013). It is therefore not possible to make any predictions about possible released of MNM from landfills, and even less of respective long-term emissions. Thus, by default, a conservative approach 
(i.e. assuming the same amount of long-term emissions of a nanoparticle like titanium as its respective bulk substance) is used here.

\section{Conclusion}

To conclude, the answer to the initial question (i.e. whether the integration of MNM in façade coatings leads to an improved environmental performance of such coating products) depends on a number of parameters:

- the MNM has to substitute an (active) ingredient of the initial paint composition;

- the effects due to the new composition (e.g. an extension of the lifetime as shown for paint systems A and C) have to overcompensate the higher impact due to the production of the MNM (e.g. as shown for paint system A due to the reduced consumption of paint $\mathrm{A} 1$ along the life cycle of the building); and

- the releases (especially by dumping unused paint) of nanoparticles have to be reduced to the lowest level possible.

In relation to the three cases examined here, only paint A shows-according to the applied boundary conditions (e.g. lifetime and release scenario)_an environmental advantage for the MNM-containing paint A1.

At the same time, this study here confirms one more time the conclusions that can be found in various review studies about the use of LCA in the area of nanotechnology (e.g. Gavankar et al. 2012; Hischier and Walser 2012; Upadhyayula et al. 2012), stressing not only the development of reliable inventory datasets for important MNM but also the urgency of the development of appropriate characterisation factors for this new type of release. The calculations done here show that the production efforts and especially the information concerning the ecological relevance of eventual releases of such MNM are of crucial importance in order to select an optimum from an ecological point of view from the alternatives MNM-containing and MNM-free coating systems. A framework for a systematic collection of the latter information (i.e. data on eventual releases of MNM) was published recently in Hischier (2014); describing a systematic way to collect this kind of data.
Acknowledgements The research was internally funded by Empa and externally by 'NanoHouse' (grant number $247^{\prime} 810$ ), a research project under the 7th framework programme of the European Commission. We herewith would like to acknowledge the support from all the project partners of 'NanoHouse' in the framework of establishing this paper and all the LCA calculations behind it, i.e. CEA (as coordinator), Empa, Consorzio Venezia Ricerche, Katholieke Universiteit Leuven, Université Joseph Fourier-Laboratoire de Géophysique Interne et Tectonophysique, Materis Paints, GFC Chimica, Akzo Nobel Coatings, and PPG Europe.

\section{References}

Al-Kattan A, Wichser A, Vonbank R, Brunner S, Ulrich A, Zuin S, Nowack B (2013) Release of $\mathrm{TiO}_{2}$ from paints containing pigment- $\mathrm{TiO}_{2}$ or nano- $\mathrm{TiO}_{2}$ by weathering. Environ Sci Process Impacts 15:2186-2193

Asmatulu E, Twomey J, Overcash MR (2012) Life cycle and nano-products: end-of-life assessment. J Nanopart Res. doi:10.1007/s11051-012-0720-0

Bauer C, Buchgeister J, Hischier R, Poganietz WR, Schebek L, Warsen J (2008) Environmental prospects in products-a framework for life cycle thinking on nano scales. J Clean Prod 16(8-9):910-926

BMU (2008) Verantwortlicher Umgang mit Nanotechnologien: Bericht und Empfehlungen der NanoKommission der deutschen Bundesregierung. Bundesministerium für Umwelt (BMU), Berlin

Bolyard SC, Reinhart DR, Santra S (2013) Behavior of engineered nanopartilces in landfill leachate. Environ Sci Technol 47:8114-8122

Doka G (2007) Life cycle inventories of waste treatment services. EMPA St Gallen, Swiss Centre for Life Cycle Inventories, Dübendorf

EC (2011) Commission Recommendation of 18 October 2011 on the definition of nanomaterial. 2011/696/EU. Official J Eur Union, Brussels (Belgium)

ECHA (2010) Guidance on information requirements and chemical safety assessment Chap R.16: Environmental Exposure Estimation. ECHA-10-G-06-EN. European Chemicals Agency

ecoinvent Centre (2010) ecoinvent data v2.2. Swiss Centre for Life Cycle Inventories, Dübendorf

Gavankar S, Suh S, Keller AF (2012) Life cycle assessment at nanoscale: review and recommendations. Int J Life Cycle Assess 17:295-303. doi:10.1007/s11367-011-0368-5

Goedkoop M, Heijungs R, Huijbregts MAJ, de Schreyver A, Struijs J, Van Zelm R (2012) ReCiPe 2008-a life cycle impact assessment method which comprises harmonised category indicators at the midpoint and the endpoint level. First edition (revised)/Report I: Characterisation. VROM-Ministery of Housing Spatial Planning and Environment, Den Haag (the Netherlands)

Gottschalk F, Sun TY, Nowack B (2013) Environmental concentrations of engineered nanomaterials: review of modelling and analytical studies. Environ Pollut 181:287-300

Hanus MJ, Harris AT (2013) Nanotechnology innovations for the construction industry. Prog Mater Sci 58:1056-1102 
Hischier R (2014) Framework for LCI modelling of nanoparticle releases along the life cycle. Int J LCA 19(4):838-849

Hischier R, Walser T (2012) Environmental sustainability assessment of engineered nanomaterials: state of art \& strategies to overcome existing gaps. Sci Total Environ 425:271-282

Huijbregts MAJ, Hauschild M, Jolliet O, Margni M, McKone T, Rosenbaum R, Van de Meent D (2010a) USEtox User Manual. USEtox Team

Huijbregts MAJ, Margni M, Jolliet O, McKone T, Van de Meent D, Rosenbaum R, Hauschild M (2010b) USEtox Chemicalspecific database: inorganics. Report version 1.00. USEtox Team

ISO (2006a) Environmental management-life cycle assessment-principles and framework. International Standardization Organization (ISO), European Standard EN ISO $14^{\prime} 040$, Geneva (Switzerland)

ISO (2006b) environmental management-life cycle assessment-requirements and guidelines. International Standardisation Organisation (ISO), European Standard EN ISO 14'044, Geneva (Switzerland)

Khan IA, Berge ND, Sabo-Attwood T, Ferguson PL, Saleh NB (2013) Singe-walled carbon nanotube transport in representative municipal solid waste landfill conditions. Environ Sci Technol 47:8425-8433

Köhler A, Som C, Helland A, Gottschalk F (2008) Studying the potential release of carbon nanotubes throughout the application life cycle. J Clean Prod 16(8-9):927-937

Linkov I, Seager T (2011) Coupling multi-criteria decision analysis, life cycle assessment and risk assessment for emerging threats. Environ Sci Technol 45:5068-5074

Ness B, Urbel-Piirsalu E, Anderberg S, Olsson L (2007) Categorising tools for sustainability assessment. Ecol Econ 60:498-508

Nowack B (2009) Is anything out there? What life cycle perspectives of nano-products can tell us about nanoparticles in the environment. Nano Today 4(1):11-12. doi:10.1016/ j.nantod.2008.10.001
Piccinno F, Gottschalk F, Seeger S, Nowack B (2012) Industrial production quantities and uses of ten engineered nanomaterials in Europe and the world. J Nanopart Res 14:1109. doi:10.1007/s11051-012-1109-9

Rebitzer G, Ekvall T, Frischknecht R, Hunkeler D, Norris G, Rydberg T, Schmidt W-P, Suh S, Weidema B, Pennington D (2004) Life cycle assessment part 1: framework, goal and scope definition, inventory analysis, and application. Environ Int 30:701-720

Roes AL, Tabak LB, Shen L, Nieuwlaar E, Patel MK (2010) Influence of using nanoobjects as filler on funtionalitybased energy use of nanocomposites. J Nanopart Res 12(6):2011-2028

Rosenbaum R, Bachmann TM, Swirsky Gold L, Huijbregts MAJ, Jolliet O, Juraske R, Koehler A, Larsen HF, MacLeod M, Margni M, McKone T, Payet J, Schuhmacher M, Van de Meent D, Hauschild M (2008) USEtox-the UNEP-SETAC toxicity model: recommended characterisation factors for human toxicity and freshwater ecotoxicity in life cycle impact assessment. Int $\mathrm{J}$ Life Cycle Assess 13:532-546

Salieri B, Righi S, Pasteris A, Olsen SI (2015) Freshwater ecotoxicity characterisation factor for metal oxide nanoparticles: a case study on titanium dioxide nanoparticle. Sci Total Environ 505:494-502

Teizer J, Venugopal M, Teizer W, Felkl J (2012) Nanotechnology and its impact on construction: bridging the gap between researchers and industry professionals. J Constr Eng Manag 138:595-604

Upadhyayula VKK, Meyer DE, Curran MA, Gonzalez MA (2012) Life cycle assessment as a tool to enhance the environmental performance of carbon nanotube products: a review. J Clean Prod 26:37-47

Walser T, Demou E, Lang DJ, Hellweg S (2011) Prospective environmental life cycle assessment of nanosilver T-shirts. Environ Sci Technol 45(10):4570-4578 